\title{
Gas Sensing Properties of Pulsed Laser Deposited Vanadium Oxide Thin Films
}

\author{
Joni Huotari ${ }^{1}$, Anita Lloyd Spetz ${ }^{1,2}$, Jyrki Lappalainen ${ }^{1}$ \\ ${ }^{1}$ Microelectronics and Material Physics Laboratories, University of Oulu, FIN-90570, Oulu, Finland \\ joni.huotari@ee.oulu.fi \\ ${ }^{2}$ Department of Physics, Chemistry and Biology, Linköping University, SE-581 83, Linköping, Sweden
}

\begin{abstract}
Vanadium oxide thin films were fabricated by pulsed laser deposition (PLD). The crystal structure and symmetry of the deposited films was studied with X-ray diffraction (XRD) and Raman spectroscopy, respectively. The surface morphology was studied with atomic force microscope (AFM). The thin films consisted mostly of $\mathrm{V}_{2} \mathrm{O}_{5}$ phase of vanadium oxides, but also of another phase, which is generally found in form of nanotubes. The measured optical transmission spectra of the films also supported the existence of different phases. The electrical resistivity of the films as a function of temperature behaved like in a typical semiconductor. The gas sensing properties of the films were characterized for different NO concentrations. The results showed a response to NO, which varied from oxidative to reducing according to the film composition.
\end{abstract}

Key words: vanadium oxide, thin film, gas sensor, NO

\section{Introduction}

The concern about pollution increases around the globe causing the regulations towards different types emissions to get tighter by time. This also relates to atmospheric gas emissions. Novel gas sensor structures and materials are needed to meet these new demands and they are studied widely in the scientific community.

Solid state semiconducting gas sensors are one of the most popular research topics in the gas sensing science. They are typically based on metal oxides $\left(\mathrm{SnO}_{2}, \mathrm{TiO}_{2}, \mathrm{WO}_{3}\right.$, etc.). Vanadium oxides are also considered as one candidate for new type of gas sensors. Different vanadium pentoxide $\left(\mathrm{V}_{2} \mathrm{O}_{5}\right)$ structures have shown sensitivity towards $\mathrm{NH}_{3}[1,2]$. Vanadium dioxide $\left(\mathrm{VO}_{2}\right)$ nanowires have been investigated as a possible $\mathrm{H}_{2}$ sensor by taking advantage of the metal-insulator transition phenomena of the material [3]. In this study, we examine the possibility to use pulsed laser deposited polycrystalline vanadium oxide thin films as NO sensors.

\section{Experimental}

Lambda Physik Compex 201 excimer laser operating at a wavelength of $308 \mathrm{~nm}$ was used to deposit vanadium oxide thin films on $1 \times 1 \mathrm{~cm}$ $c$-cut $\mathrm{Al}_{2} \mathrm{O}_{3}$ substrates. The pulse repetition rate was $5 \mathrm{~Hz}$. The target used was a pure ceramic $\mathrm{V}_{2} \mathrm{O}_{5}$ target and the laser pulse energy densities were $\mathrm{I}=2.55 \mathrm{~J} / \mathrm{cm}^{2}$ and $\mathrm{I}=1,275$ $\mathrm{J} / \mathrm{cm}^{2}$. The in-situ substrate temperatures were $\mathrm{T}=400{ }^{\circ} \mathrm{C}$ and $\mathrm{T}=500{ }^{\circ} \mathrm{C}$. The deposition chamber was first pumped to a base pressure of $\sim 5 \times 10^{-5} \mathrm{mbar}$ and then oxygen partial pressure $\left(p\left(\mathrm{O}_{2}\right)\right)$ of $1 \times 10^{-2}$ mbar or $1.5 \times 10^{-2}$ mbar was added in the chamber. One of the samples was post annealed in an oven at 400 ${ }^{\circ} \mathrm{C}$ for $1 \mathrm{~h}$.

Crystal structure of the films was studied using Philips PW1380 $\theta-2 \theta$ X-ray diffraction (XRD), and HORIBA Jobin Yvon LabRAM HR800 argon-ion laser with a wavelength of $488 \mathrm{~nm}$ was used to measure the Raman spectra. The surface morphology was studied using Veeco Dimension 3100 atomic force microscope (AFM). Optical transmission spectra of the films were measured between wavelengths of 250$2250 \mathrm{~nm}$ by using Varian 5000 UV-vis-NIR spectrophotometer.

Photolithography processes and rf-sputtering was used to manufacture $300 \mathrm{~nm}$ thick platinum interdigital electrodes (IDE) on the thin films. The electrical resistivity as a function of temperature, and the NO response was measured using a probe station together with Linkam THMSE600 heating stage connected to Keithley 2636A sourcemeter and to Agilent 
3458A multimeter. A gas blender was used to mix the NO gas with a background gas of synthetic air. The gas measurement system was controlled through LabVIEW software.

\section{Results}

The pulsed laser deposition parameters of three different vanadium oxide thin film compositions are shown in Table 1. The film $A$ was first amorphous according to XRD data, but it was then post annealed in an oven at $400{ }^{\circ} \mathrm{C}$ for $1 \mathrm{~h}$.

Tab. 1: The deposition conditions of different pulsed laser deposited vanadium oxide thin films

\begin{tabular}{|c|c|c|c|}
\hline $\begin{array}{c}\text { Thin } \\
\text { film }\end{array}$ & $\begin{array}{c}\text { Substrate } \\
\text { temperature } \\
\mathbf{T} /{ }^{\circ} \mathbf{C}\end{array}$ & $\begin{array}{c}\text { Oxygen } \\
\text { partial } \\
\text { pressure } \\
\mathbf{p}\left(\mathbf{O}_{2}\right) / \\
\text { mbar }\end{array}$ & $\begin{array}{c}\text { Laser } \\
\text { pulse } \\
\text { energy } \\
\text { density } \mathbf{~ I} \\
\mathbf{J}^{\prime} \mathbf{c m}^{2}\end{array}$ \\
\hline A) & 400 & $1.0 \times 10^{-2}$ & 1.275 \\
\hline B) & 400 & $1.5 \times 10^{-2}$ & 2.55 \\
\hline C) & 500 & $1.5 \times 10^{-2}$ & 2.55 \\
\hline
\end{tabular}

In Fig. 1., the Raman spectra of the deposited films are presented. According to the data, the post annealed film A) had a phase co-existence of a major $\mathrm{V}_{2} \mathrm{O}_{5}$ phase and another phase. In films $B$ ) and $C$ ) the presence of the other phase, identified as a structure found in $\mathrm{VO}_{\mathrm{x}}-$ NT nanotubes [4, 5], was clearly stronger. These nanotubes are usually fabricated with a chemical process and they are formed as rolls with layered walls. Probably this phase in these films was formed as layered structure of $\mathrm{VO}_{x}$ instead of nanotubes. In the film $B$ ) the $\mathrm{V}_{2} \mathrm{O}_{5}$ phase was still dominating over the $\mathrm{VO}_{\mathrm{x}}-\mathrm{NT}$ type phase, but in the film $\mathrm{C}$ ) the $\mathrm{V}_{2} \mathrm{O}_{5}$ phase was almost gone and the $\mathrm{VO}_{\mathrm{x}}-\mathrm{NT}$ type phase was dominating.

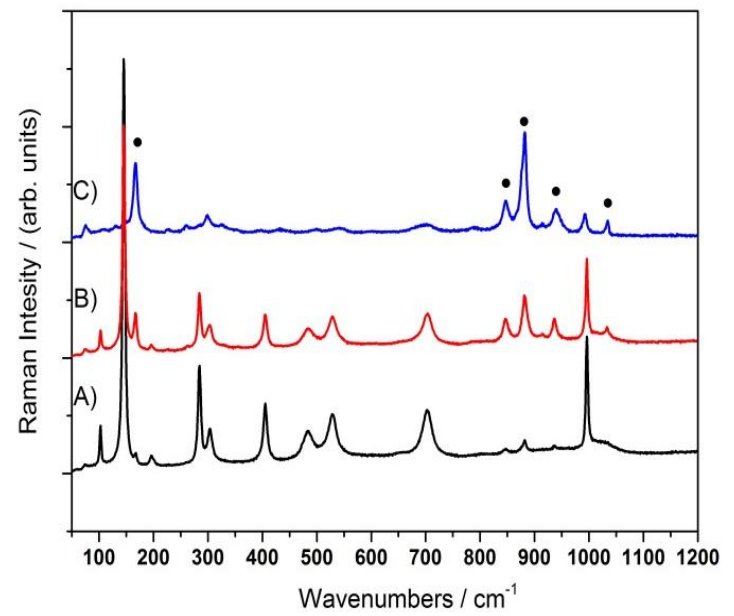

Fig. 1. Raman spectra of three different types of vanadium oxide thin films: A) $\mathrm{V}_{2} \mathrm{O}_{5}$ thin film, B) the $\mathrm{V}_{2} \mathrm{O}_{5}$ phase dominating over the $\mathrm{VO}_{x}-\mathrm{NT}$ type phase and $C$ ) the $\mathrm{VO}_{x}-\mathrm{NT}$ phase dominating over the $\mathrm{V}_{2} \mathrm{O}_{5}$ phase. The black circles represent the Raman modes typical to the $V O_{x}-N T$ type phase. The other peaks arise from the $\mathrm{V}_{2} \mathrm{O}_{5}$ phase.

The X-ray diffraction curves of three different types of vanadium oxide thin films are shown on Fig.2. The results show that films $A$ ) and $B$ ) were polycrystalline $\mathrm{V}_{2} \mathrm{O}_{5}$ thin films with a strong (001) orientation, but in film $\mathrm{C}$ ) the phase was almost gone.

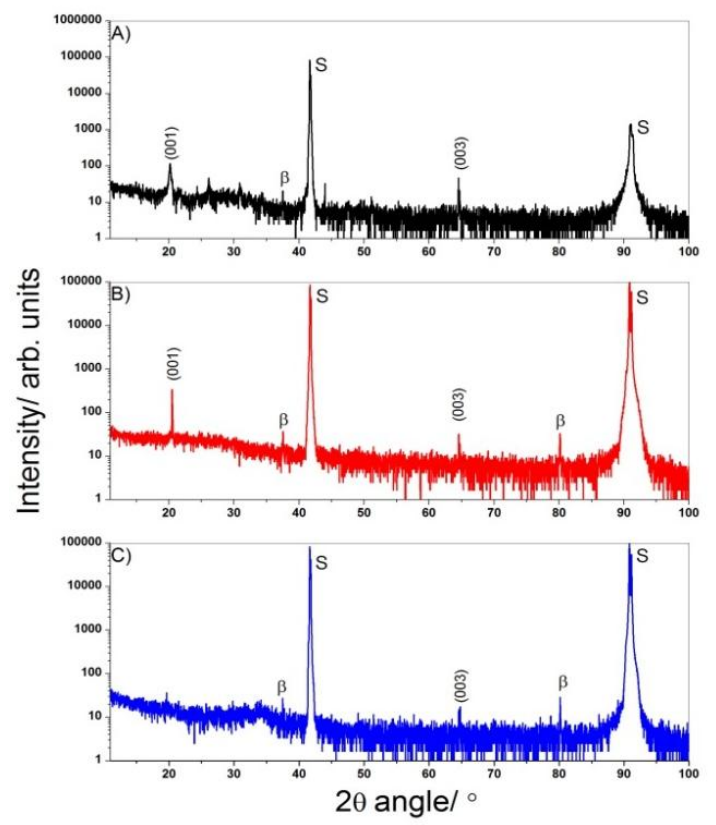

Fig. 2. X-ray diffraction graphs of the three different types of vanadium oxide thin films.

The AFM images of the three films can be seen in Fig. 3. They all showed a polycrystalline surface morphology, and in film B) the largest variation in the surface height was obtained. Also some droplets from the PLD process were noticed on the surfaces.
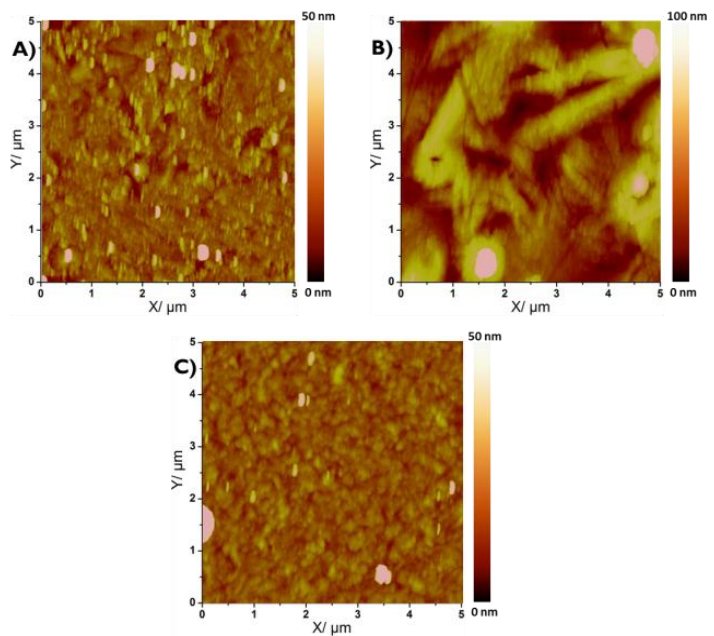

Fig. 3. Atomic force microscopy images of the thin films: A) a polycrystalline $\mathrm{V}_{2} \mathrm{O}_{5}$ thin film, B) the $\mathrm{V}_{2} \mathrm{O}_{5}$ phase dominating over the $V O_{x}-N T$ type phase and C) the $\mathrm{VO}_{x}-\mathrm{NT}$ type phase dominating over the $\mathrm{V}_{2} \mathrm{O}_{5}$ phase. 
The optical transmittance spectra of the three films are shown in Fig. 4. Film $A$ ) showed a typical spectrum of a $\mathrm{V}_{2} \mathrm{O}_{5}$ phase. In film $\mathrm{B}$ ) the $\mathrm{VO}_{\mathrm{x}}-\mathrm{NT}$ type phase clearly transformed the transmittance value to smaller percentage at lower wavelengths. When the $\mathrm{VO}_{\mathrm{x}} \mathrm{NT}$ phase was dominant in film $\mathrm{C}$ ), the transmittance value dropped to the same direction even more.

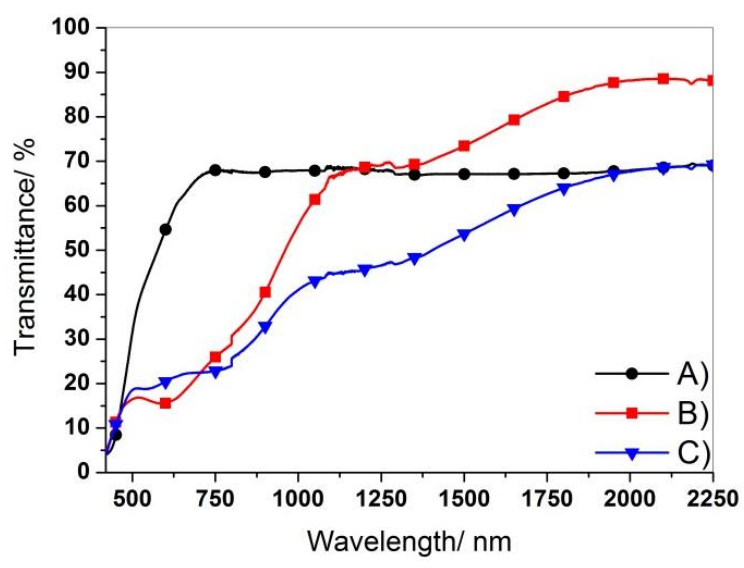

Fig. 4. The transmittance spectra of the different vanadium oxide thin films: A) a polycrystalline $\mathrm{V}_{2} \mathrm{O}_{5}$ thin film, B) $\mathrm{V}_{2} \mathrm{O}_{5}$ phase dominating over $\mathrm{VO}_{x}-\mathrm{NT}$ type phase and C) $V^{-} O_{x}-N T$ type phase dominating over $\mathrm{V}_{2} \mathrm{O}_{5}$ phase.

In Fig. 5., the electrical resistivity as a function of temperature is shown. When the resistivity of the thin films was measured between the temperatures RT - $350{ }^{\circ} \mathrm{C}$, it decreased exponentially in all of the films. This is a very typical behavior in semiconducting materials. The highest value of resistivity was in film $\mathrm{B}$ ), where the $\mathrm{V}_{2} \mathrm{O}_{5}$ phase was dominating over the $\mathrm{VO}_{\mathrm{x}}-\mathrm{NT}$ type phase, and the lowest value was measured from film $\mathrm{C}$ ), where the $\mathrm{VO}_{\mathrm{x}}-\mathrm{NT}$ type phase was dominant. Some hysteresis can also be seen in the figures, when the temperature was cycled back from $350{ }^{\circ} \mathrm{C}$ to $\mathrm{RT}$.
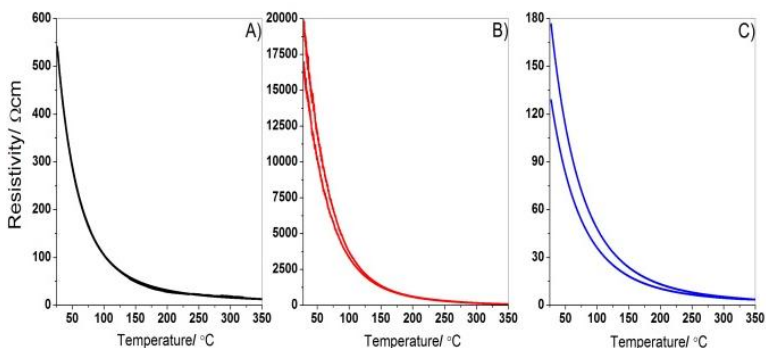

Fig. 5. The electrical resistivity as function of temperature for different vanadium oxide thin films: A) a polycrystalline $\mathrm{V}_{2} \mathrm{O}_{5}$ thin film, B) the $\mathrm{V}_{2} \mathrm{O}_{5}$ phase dominating over the $\mathrm{VO}_{x}-\mathrm{NT}$ type phase and $C$ ) the $V_{O_{x}}-N T$ type phase dominating over the $\mathrm{V}_{2} \mathrm{O}_{5}$ phase.

The measured electrical response of the films for different nitric oxide (NO) concentrations is presented in Fig. 6. The measurement temperature was $290{ }^{\circ} \mathrm{C}$. All of the films showed some response to the gas injection. In films A) and B) the response was clear, although the sensitivity was quite modest. In film C) the response was very small and the background in the measurement results was strong. That is why the response of film $\mathrm{C}$ ) is background corrected and it shows only the change in the measured resistivity, which is modest. However, an interesting phenomenon was noticed from the results. In the polycrystalline $\mathrm{V}_{2} \mathrm{O}_{5}$ thin film, the resistivity decreased every time the NO gas was injected to the measurement chamber. On the other hand, when the film had a dominating $\mathrm{V}_{2} \mathrm{O}_{5}$ phase mixed with a minor $\mathrm{VO}_{\mathrm{x}}-\mathrm{NT}$ type phase in film $B$ ), the resistivity increased with the added gas. But when $\mathrm{VO}_{\mathrm{x}}-\mathrm{NT}$ type phase was a major phase in film $\mathrm{C}$ ) the resistivity dropped again according to $\mathrm{NO}$ injection. The reaction between the films and the NO gas turned from reducing (film $A)$ ) to oxidative (film $B$ )) and back (film C)).

\section{Conclusions}

The gas sensing properties of pulsed laser deposited vanadium oxide thin films were studied. The X-ray diffraction and Raman spectroscopy measurement results showed the co-existence of polycrystalline $\mathrm{V}_{2} \mathrm{O}_{5}$ phase and $\mathrm{VO}_{\mathrm{x}}-\mathrm{NT}$ type phase in the films. The atomic force microscopy and optical transmittance spectrum measurements gave support for these conclusions. The $\mathrm{VO}_{\mathrm{x}}-\mathrm{NT}$ type phase usually appears as nanotubes with layered walls. It is likely that these films have only the layered structure similar to tube walls in them, not the tubular structure itself.

The electrical resistivity as a function of temperature decreased exponentially in all of the thin films and interestingly the film with the dominating $\mathrm{VO}_{\mathrm{x}}-\mathrm{NT}$ type phase had the lowest value of resistivity and the film with coexistence of major $\mathrm{V}_{2} \mathrm{O}_{5}$ phase and minor $\mathrm{VO}_{\mathrm{x}^{-}}$ NT type phase had the highest value.

Response to NO was measured from all the thin films and the reaction between the sample and gas changed from reducing to oxidative according to film composition. Films with dominant phases of $\mathrm{V}_{2} \mathrm{O}_{5}$ and $\mathrm{VO}_{\mathrm{x}}-\mathrm{NT}$ had $\mathrm{a}$ reducing reaction. Commonly, $\mathrm{V}_{2} \mathrm{O}_{5}$ material is considered an n-type semiconductor and the reaction with NO can be either oxidative, through addition of oxygen to the surface and formation of nitrogen which desorbs. But NO may also be oxidized by surface oxygen to $\mathrm{NO}_{2}$, that is NO then acts as a reducing gas. This study shows that the mixed phase of minor $\mathrm{VO}_{\mathrm{x}}-\mathrm{NT}$ and a major $\mathrm{V}_{2} \mathrm{O}_{5}$ provided enhanced gas sensing capability of the vanadium oxide thin films. 

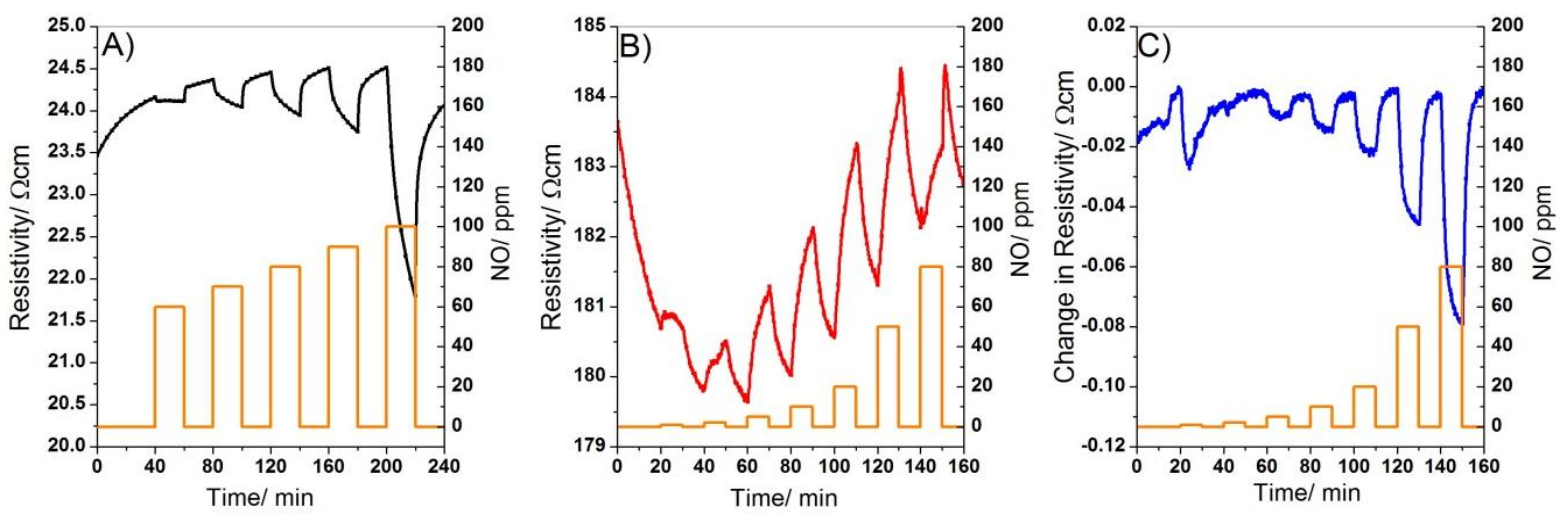

Fig. 6 The electrical response of the vanadium oxide thin films for different NO concentrations: A) a polycrystalline $\mathrm{V}_{2} \mathrm{O}_{5}$ thin film, B) the $\mathrm{V}_{2} \mathrm{O}_{5}$ phase dominating over the $\mathrm{VO}_{x}-\mathrm{NT}$ type phase and C) the VO $\mathrm{O}_{x}-\mathrm{NT}$ type phase dominating over the $\mathrm{V}_{2} \mathrm{O}_{5}$ phase. The background gas was $20 \% \mathrm{O}_{2}$ in $\mathrm{N}_{2}$ and the measurement temperature was $290^{\circ} \mathrm{C}$.

\section{Acknowledgements}

Tekes is acknowledged for financial support through the CHEMPACK project \#1427/31/2010. J. Huotari acknowledges the Riitta and Jorma J. Takanen foundation and the Walter Alhström foundation.

\section{References}

[1] V. Modaferri, G. Panzera, A. Donato, P.L. Antonucci, C. Cannilla, N. Donato, D. Spadaro, G. Neri, Highly Sensitive Ammonia Resistive Sensor Based on Electrospun $\mathrm{V}_{2} \mathrm{O}_{5}$ fibers, Sensors and Actuators B: Chemical 163, 61-68 (2012); doi: 10.1016/j.snb.2012.01.007

[2] G. Rizzo, A. Arena, A. Bonavita, N. Donato, G. Neri, G. Saitta, Gasochromic Response of Nanocrystalline Vanadium Pentoxide Films Deposited from Ethanol Dispersions, Thin Solid Films 518, 7124-7127 (2010); doi: 10.1016/j.tsf.2010.07.010

[3] J.W. Byon, M.B. Kim, M.H. Kim, S.Y. Kim, S.H. Lee, B.C. Lee, J.M. Baik, Electrochemically Induced Highly Responsive and Highly Selective Vanadium Oxide Hydrogen Sensor Based in Metal-Insulator Transition, The Journal of Physical Chemistry C 116, 226-230 (2012); doi: 10.1021/jp2080989

[4] A.G. Souza Filho, O.P. Ferreira, E.J.G. Santos, J. Mendes Filho, O.L. Alves, Raman Spectra in Vanadate Nanotubes Revisited, Nano Letters 4, 2099-2104 (2004); doi: 10.1021/nI0488477

[5] X. Liu, C. Huang, J. Qiu, Y. Wang, The Effect of Thermal Annealing and Laser Irridiation on the Microstructure of Vanadium Oxide Nanotubes, Applied Surface Science 253, 2747-2751 (2006); doi: 10.1016/j.apsusc.2006.05.041 